\title{
Article \\ The Effect of Finely-Grinded Crushed Brick Powder on Physical and Microstructural Characteristics of Lightweight Concrete
}

\author{
Hussein Al-kroom ${ }^{1, *(D)}$, May M. Atyia ${ }^{2, *(\mathbb{D})}$, Mohamed G. Mahdy ${ }^{2}$ and Mohamed Abd Elrahman ${ }^{2}(\mathbb{D}$ \\ 1 Civil Engineering Department, The University of Jordan, Amman 11942, Jordan \\ 2 Structural Engineering Department, Faculty of Engineering, Mansoura University, Mansoura 35516, Egypt; \\ mmahdy@mans.edu.eg (M.G.M.); mohamedattia@mans.edu.eg (M.A.E.) \\ * Correspondence: h.alkroom@ju.edu.jo (H.A.-k); may.atyia92@gmail.com (M.M.A.)
}

Citation: Al-kroom, H.; Atyia, M.M.; Mahdy, M.G.; Abd Elrahman, M. The Effect of Finely-Grinded Crushed Brick Powder on Physical and Microstructural Characteristics of Lightweight Concrete. Minerals 2022, 12, 159. https://doi.org/10.3390/ $\min 12020159$

Academic Editor: Dawei Wang

Received: 25 December 2021

Accepted: 26 January 2022

Published: 27 January 2022

Publisher's Note: MDPI stays neutral with regard to jurisdictional claims in published maps and institutional affiliations.

Copyright: (C) 2022 by the authors. Licensee MDPI, Basel, Switzerland. This article is an open access article distributed under the terms and conditions of the Creative Commons Attribution (CC BY) license (https:// creativecommons.org/licenses/by/ $4.0 /)$.

\begin{abstract}
The utilization of waste crushed clay brick (CB) in concrete reduces its harmful impacts on the environment as it can be found in many places around the world. This research studies the possibility of using clay brick powder (CBP) as a filler material to produce lightweight concrete as it has been exposed to high temperatures during manufacturing of the bricks, which increases its pozzolanic reactivity. The effect of using an air-entraining agent (AEA) for additional pore formation on concrete performance was evaluated. Eight mixtures were prepared and examined to achieve the research objectives. Concrete flowability, dry density, compressive strength, ultrasonic pulse velocity, thermal conductivity, sorptivity, and porosity were measured. Additionally, scanning electron microscopy, X-ray diffraction, thermo-gravimetric analysis, and mercury intrusion porosimetry were used to analyze the microstructure characteristics of the concrete. The results indicate that the use of CBP as filler material enhances the mechanical and durability characteristics of the concrete. In contrast, adding an AEA has negative effects on concrete's mechanical and durability properties, but on the other hand, its use enhances the thermal properties of the concrete.
\end{abstract}

Keywords: porosity; air-entraining agent; crushed clay brick concrete; microstructure

\section{Introduction}

Construction and demolition wastes represent serious environmental problems as they occupy rare landfills. These wastes cause damage to the land as they dissolve, producing harmful substances which pollute the soil and water [1,2]. One of these wastes is crushed clay brick (CB) waste. Brick is also considered a waste material when it breaks during the production process or when it does not meet standards. CB waste is transported to landfills or dumped into designated sites [3,4]. This waste is increasing annually, which increases the need for huge waste landfills [5]. Due to the limited number of landfills, CB waste occupies valuable landfills and damages soil structure, resulting in poor grain yield. Waste storage has become a serious environmental problem. Therefore, CB waste should be reused to significantly reduce the waste that will be transported to landfills [6]. CB's first use in concrete was in 1860. After that, it was used as aggregate in concrete for the first time after World War II [7]. CB waste is usable in building materials based on concrete as an artificial recycled aggregate [8]. Aggregates represent about $(60 \%-75 \%)$ of concrete volume. Therefore, if CB waste were to be recycled as aggregates in concrete production, this would preserve significant natural aggregate resources and consume large quantities of $C B$ wastes [9]. The influence of utilizing $C B$ as coarse aggregate in concrete has been investigated in several studies [9-13]. The incorporation of $\mathrm{CB}$ as fine aggregate in the concrete industry has been evaluated [14-18]. The utilization of CB as coarse and fine aggregates in concrete production has been investigated [1,2]. Using CB as aggregate decreases the concrete workability [14]. The compressive strength of concrete made with $\mathrm{CB}$ as aggregate is weaker than that of the concrete produced with normal aggregates [10]. However, utilizing it as aggregate in concrete reduces the concrete weight [1]. 
Lightweight concrete has been widely used in construction for many years. Its use is preferred because of its low density and good sound and thermal insulation [10,19]. Using this type of concrete decreases the structure's dead weight, which causes a reduction in the construction cost as its use reduces the foundation size and also reduces the size of the structural elements [20]. Lightweight concrete has a wide range of densities, which makes its application field wider. It can be classified into two types: cellular concrete produced by creating air voids in the concrete and lightweight aggregate concrete produced using lightweight aggregate from natural sources or manufactured with raw materials [21,22]. CB aggregates can be used to produce lightweight aggregate concrete. Its use would not only reduce CB waste but also produce lightweight aggregate concrete with more environmentally, friendly, and cheaper materials [2]. The production of lightweight concrete using $\mathrm{CB}$ as an aggregate has been investigated as shown in Table 1.

Table 1. Summary of research that examined the production of lightweight concrete with CB.

\begin{tabular}{cccc}
\hline References & Production & Compressive Strength (Mpa) & Dry Density (kg/m $\left.{ }^{\mathbf{3}}\right)$ \\
\hline Zhao et al., 2018 [2] & Lightweight aggregate concrete & $32.6-40.2$ & $1729-1850$ \\
Atyia et al., 2021 [4] & $\begin{array}{c}\text { Structural lightweight } \\
\text { aggregate concrete }\end{array}$ & $\geq 27$ & $\leq 1860$ \\
Wongsa et al., 2018 [22] & Lightweight geopolymer concrete & $8.2-18.3$ & $1685-1749$ \\
Noaman et al., 2021 [23] & $\begin{array}{c}\text { Structural lightweight } \\
\text { aggregate concrete }\end{array}$ & $27.2-27.8$ & $1926-1960$ \\
\hline
\end{tabular}

In the process of air entrainment, small air bubbles are generated in the concrete. These air bubbles become part of the cement matrix [24]. Three methods can be used to achieve these air bubbles and produce air-entraining concrete. The first method is achieved by adding an air-entraining agent (AEA) with other concrete components during the mixing process. The second one is achieved by using air-entraining cement, which includes an air-entraining agent as an addition interground with the clinker during the manufacturing process of the cement. The third method is a combination of the first method and second method. AEA addition can improve the resistance to freezing and thawing as it produces dispersed and distributed air bubbles [25]. The effect of adding an AEA with different dosages on the characteristics of the concrete was studied [20,26-29]. Deng et al. used Rosin acid sodium with a dosage of $0.05 \%$ of cement weight as an AEA. Adding an AEA causes an increase in the ratio of mesopores and macropores, which causes a decrease in the dry density [26]. With increasing the AEA content, the proportion of the pores with a diameter more than $0.3 \mathrm{~mm}$ increases [27]. The concrete compressive strength decreases with increasing the percentage of AEA [27-29]. The utilization of the AEA lowers the tensile strength [29]. The utilization of the AEA improves the frost resistance of the concrete as it increases the porosity of the concrete [26]. Increasing the AEA causes an increase in the water penetration depth [25]. Increasing the AEA content increases the water absorption of concrete $[28,29]$. The application of the AEA increases the air permeability and the moisture content [29]. The influence of utilizing the AEA in producing the mortar was studied. The compressive strength and the unit weight decreased with increasing the AEA content [30].

Most studies have investigated the effect of utilizing $\mathrm{CB}$ as fine aggregate in producing cement-based materials or coarse aggregate in producing concrete. A few investigations have studied the properties of concrete containing CB as fine and coarse aggregates. Only a few studies have studied the effect of utilizing clay brick powder (CBP) as filler material in producing cement-based materials. A few studies investigated the effect of adding an AEA in cement-based materials.

The main objectives of this research were to determine the effect of using CBP as a filler material and the influence of adding the AEA in crushed clay brick concrete. The fresh and hardened properties of the CB aggregate concrete were studied in this research. The absorption of the obtained concrete was determined to measure the durability-related characteristics. The thermal conductivity of the concrete was evaluated to determine the 
insulation properties of the obtained concrete. Scanning electron microscopy (SEM), X-ray diffraction (XRD), thermo-gravimetric analysis (TGA), and mercury intrusion porosimetry (MIP) were used to analyze the microstructural properties of the obtained concrete.

\section{Materials}

CB from construction wastes was utilized in this investigation. It was manually crushed and graded into sizes to be used as coarse aggregate and fine aggregate. Coarse crushed clay brick aggregate (CCB) with a maximum nominal size of $12.5 \mathrm{~mm}$ was utilized as coarse aggregate. Fine crushed clay brick aggregate (FCB) with 2.74 fineness modulus was used as fine aggregate. Aggregates were tested according to EN ISO 19595 [31]. Clay brick powder (CBP) with particle size less than $0.125 \mathrm{~mm}$ was used as filler material. It was used as a replacement material for fine aggregate. Figure 1 shows the crushed clay brick aggregate (CCB, FCB, and CBP). Ordinary Portland cement CEM I $52.5 \mathrm{~N}$ meets the requirements of ES 4756-1 [32]. Silica fume (SF) complying with ASTM C 1240 [33] was used as a partial replacement for cement. Oxide compositions of cement, SF, and CBP are illustrated in Table 2. Figure 2 presents the particle size distributions of the used materials. Superplasticizer (SP), which confirms the requirements of ASTM C 494 type F [34], was utilized as a high water reducer. Aqueous synthetic resin-type dispersions as air-entraining concrete admixture was used as an AEA. It complies with ASTM C 260-81 [35]. Its density is $1.01 \mathrm{~kg} / \mathrm{L}$. It was used to produce lighter concrete.

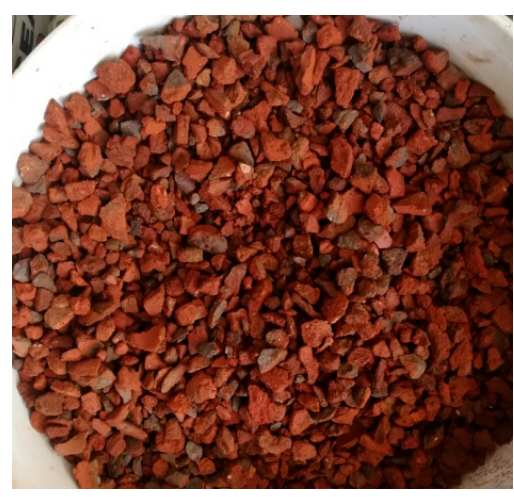

(a)

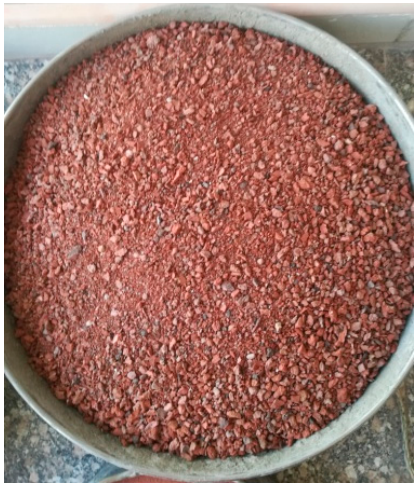

(b)

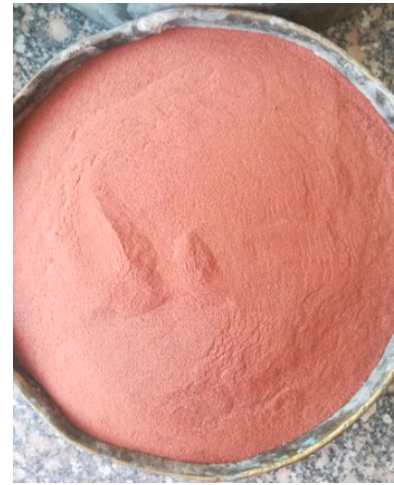

(c)

Figure 1. Crushed clay brick aggregate: (a) CCB (b), FCB, and (c) CBP.

Table 2. Oxide compositions of the used materials.

\begin{tabular}{cccc}
\hline $\begin{array}{c}\text { Oxide Composition } \\
(\mathbf{\%})\end{array}$ & Cement & SF & CBP \\
\hline $\mathrm{SiO}_{2}$ & 20.15 & 90.18 & 51.6 \\
$\mathrm{Fe}_{2} \mathrm{O}_{3}$ & 3.25 & 0.35 & 10.40 \\
$\mathrm{Al}_{2} \mathrm{O}_{3}$ & 6.1 & 0.47 & 14.0 \\
$\mathrm{CaO}$ & 62.6 & 0.56 & 7.15 \\
$\mathrm{MgO}$ & 1.9 & 4.32 & 1.67 \\
$\mathrm{SO}_{3}$ & 2.4 & 0.26 & 7.66 \\
$\mathrm{TiO}_{2}$ & 0.3 & 0.22 & 1.82 \\
Loss on Ignition & 1.7 & 2.9 & 1.74 \\
\hline
\end{tabular}




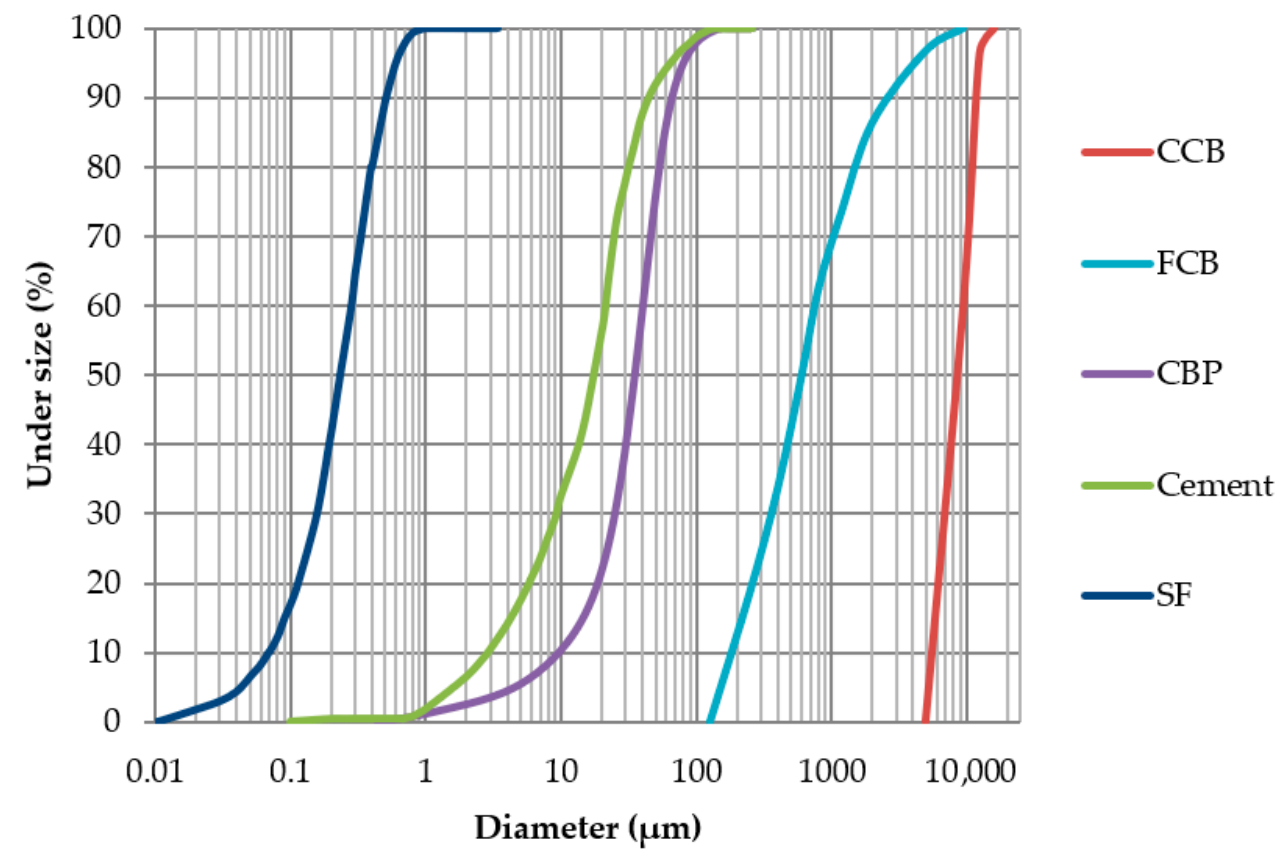

Figure 2. Particle size distributions of coarse crushed clay brick aggregate (CCB), fine crushed clay brick aggregate (FCB), clay brick powder (CBP), cement, and silica fume (SF).

\section{Mix Proportioning}

To achieve the objective of the research, eight mixtures were designed and prepared. Table 3 presents the proportions of the concrete mixtures that were designed using the absolute volume method. CBP was used as fine aggregate with different ratios $(0 \mathrm{wt} . \%$, $10 \mathrm{wt} . \%, 20 \mathrm{wt} . \%$, and 30wt.\%) in (MF0, MF10, MF20, and MF30), respectively. In other mixes, an AEA was used with $(0.25 \%, 0.5 \%, 0.75 \%$, and $1 \%)$ weight ratios in cementitious materials in mixes (MF30-0.25, MF30-0. 5, MF30-0.75, and MF30-1), respectively. All aggregates were used in saturated and surface dry (SSD) conditions before mixing. A mixer with a capacity of $0.07 \mathrm{~m}^{3}$ was utilized to mix the components of the mixtures. Coarse and fine aggregates were mixed in the mixer for $2 \mathrm{~min}$, and then cementitious materials were added and mixed for $2 \mathrm{~min}$. A total of $2 / 3$ of the water was added and mixed for $2 \mathrm{~min}$. Then $1 / 3$ of the water mixed with SP was added and mixed for $2 \mathrm{~min}$. In mixes containing an AEA, it was added to the mixer and mixed for only an extra $2 \mathrm{~min}$. The flowability of the obtained concrete was immediately measured, and then the fresh concrete was cast in steel molds. The samples were demolded after $24 \mathrm{~h}$ and then cured in water. The samples were then taken out of the water at the testing date, and the hardened properties were measured. SEM, XRD, TGA, and MIP were also analyzed.

Table 3. Mixture proportions of the concrete $\left(\mathrm{kg} / \mathrm{m}^{3}\right)$.

\begin{tabular}{|c|c|c|c|c|c|c|c|c|}
\hline \multirow{2}{*}{ Mix Label } & \multicolumn{8}{|c|}{ Components $\left(\mathrm{kg} / \mathrm{m}^{3}\right)$} \\
\hline & CCB & FCB & CBP & Cement & SF & water & SP & AEA \\
\hline MF0 & 700 & 700 & - & 432 & 48 & 168 & 7.2 & - \\
\hline MF10 & 700 & 630 & 70 & 432 & 48 & 168 & 7.2 & - \\
\hline MF20 & 700 & 560 & 140 & 432 & 48 & 168 & 7.2 & - \\
\hline MF30 & 700 & 490 & 210 & 432 & 48 & 168 & 7.2 & - \\
\hline MF30-0.25 & 700 & 490 & 210 & 432 & 48 & 168 & 7.2 & 1.2 \\
\hline MF30-0.5 & 700 & 490 & 210 & 432 & 48 & 168 & 7.2 & 2.4 \\
\hline MF30-0.75 & 700 & 490 & 210 & 432 & 48 & 168 & 7.2 & 3.6 \\
\hline MF30-1 & 700 & 490 & 210 & 432 & 48 & 168 & 7.2 & 4.8 \\
\hline
\end{tabular}




\section{Experimental Work}

The influence of utilizing CBP as filler material was studied in this investigation. Additionally, the AEA's influence was also studied. The fresh and hardened characteristics of the concrete were evaluated. The flowability was measured by using the slump flow test according to EN 12350-8 [36]. It was measured using a steel cone with a $30 \mathrm{~cm}$ height, $20 \mathrm{~cm}$ lower diameter, and $10 \mathrm{~cm}$ upper diameter. It was placed with the bigger opening at the bottom on a smooth surface. It was filled with fresh concrete, and the surface was leveled. Then, the cone was slowly raised, and fresh concrete would flow. Two perpendicular diameters of the concrete were measured to obtain the mean flow diameter value. The test was performed three times to obtain the average flow diameter value.

To evaluate the hardened characteristics of the concrete, the following tests were used. The dry density of the concrete was evaluated as per EN 12390-7 [37]. Three 28-day-old specimens (100 mm cubes) were utilized to evaluate the dry density. The dry mass of each specimen was determined after drying at $105 \pm 5{ }^{\circ} \mathrm{C}$ until reaching a constant mass. The dry density was then calculated by dividing the dry mass by the measured volume. The average value of the three specimens was used to determine the dry density. The compressive strength of the concrete was evaluated following BS EN 12390 [38] at 7, 28, and 91 days. Three $100 \mathrm{~mm}$ cube specimens of each age were used to determine the average compressive strength. A hydraulic testing machine with a capacity of 100 tons and an accuracy of 0.2 ton was used to test the samples. The direct transmission method was utilized to evaluate the ultrasonic pulse velocity (UPV) as specified in ASTM C597-16 [39]. Three dried specimens with dimensions of $100 \times 100 \times 100 \mathrm{~mm}^{3}$ of each mixture after 28 days were used to obtain the average value of the UPV. It was calculated by using the computed time and the concrete length. The concrete sorptivity was measured using three $100 \mathrm{~mm}$ cubes at 28 days. It was evaluated following EN ISO 15148 [40]. Thermal conductivity was measured to ascertain the thermal insulation capacity of the concrete. It represents the heat loss passing through dried concrete strips with dimensions of $100 \times 100 \times 30 \mathrm{~mm}^{3}$. An electric heater was utilized as a heat source. A heat recorder and thermocouples were used to measure the temperature. Fourier's equation was used to calculate the thermal conductivity coefficient. Concrete cylinders with a diameter of $25 \mathrm{~mm}$ and height of $65 \mathrm{~mm}$ taken from the core of the hardened cube were utilized to evaluate the concrete porosity. The samples were dried to constant mass, and then the dry density of the sample was measured, and the samples were placed in the helium pycnometer to measure the specific density of the concrete. The average specific density was be calculated from the three measured specific densities. Equation (1) was utilized to obtain the porosity of the hardened concrete at 91 days.

$$
\varnothing_{H . P}=\frac{\rho_{s}-\rho_{d}}{\rho_{s}} \times 100
$$

where:

$\varnothing_{H . P}$ : Total porosity of the concrete (\%),

$\rho_{s}$ : Specific density $\left(\mathrm{gm} / \mathrm{cm}^{3}\right)$,

$\rho_{d}$ : Dry density $\left(\mathrm{gm} / \mathrm{cm}^{3}\right)$.

For microstructural investigations, SEM, XRD, TGA, and MIP were measured as follows. SEM was utilized to analyze the influence of utilizing CBP as filler material and the effect of using different dosages of the AEA. The microstructure investigations of MF0, MF30, MF30-0.5, and MF30-1 were analyzed by SEM at 91 days. A JEOL JSM-6510LV scanning electron microscope was used to study the microstructure of the concrete (Electron Microscopy Unit, Mansoura University, Egypt). An XRD test was performed to ascertain the concrete microstructure of the selected samples (MF0, MF30, MF30-0.5, and MF30-1) after 91 days. Dry concrete cubes with dimensions of $\left(100 \times 100 \times 100 \mathrm{~mm}^{3}\right)$ were ground into powders and analyzed using an X-ray diffractometer. Samples were scanned with a speed of $2^{\circ} / \mathrm{min}$ over an interval from $5^{\circ}$ to $50^{\circ}$. An $X^{\prime}$ PertHighScore 2006 program with the ICDD (International Center for Deviation Data) database was used to measure 
the most probable phases (HBRC, Cairo, Egypt). For more microstructure investigations, samples (MF0, MF30, MF30-0.5, and MF30-1) were analyzed by TGA. Concrete cubes at 91 days were ground into powders. Samples were heated at a rate of $20^{\circ} \mathrm{C} / \mathrm{min}$ up to $1000{ }^{\circ} \mathrm{C}$ under a dynamic nitrogen atmosphere by a TGA-50 thermal analyzer (HBRC, Cairo, Egypt). MIP was utilized to assess the pore structure of the concrete at 91 days. The samples were small pieces with diameters between $2 \mathrm{~mm}$ and $4 \mathrm{~mm}$ taken from the central part of hardened concrete. Before the test, samples of MF0, MF30, MF30-0.5, and MF30-1 were dried. Then, the dried samples were loaded in the testing chamber of an MIP device (Micromeritics pore sized 9320, automatic mercury intrusion pore size analyzer). The pressure was vacuumed from the testing chamber, then the mercury intrusion pressure was performed progressively from $1 \mathrm{psi}(8.6 \mathrm{kPa})$ to a maximum pressure of $30,000 \mathrm{psi}$ $(206.84 \mathrm{MPa})$. The pore size of the specimens, which was within the range from $6 \mathrm{~nm}$ to about $170 \mu \mathrm{m}$, was detected and recorded. The equilibrium time for each applied pressure step was set as $10 \mathrm{~s}$. The contact angle between the mercury and the pores was $130^{\circ}$. The surface tension of the mercury was 485 dynes/ $\mathrm{cm}$, and its density was $13.53 \mathrm{~g} / \mathrm{mL}$ (CMRDI, Cairo, Egypt).

\section{Results and Discussion}

\subsection{Fresh Properties (Flowability)}

The slump flow test was used to evaluate the performance of the fresh concrete. The results of the slump flow test for the fresh concrete are illustrated in Figure 3. The values were found to be between 500 and $700 \mathrm{~mm}$ without any segregation. The figure shows that using CBP as filler material increased the flowability of the fresh concrete. There was a $17.6 \%$ increase in the flowability of MF30 compared with MF0. This may be due to the increased powder content in the fresh concrete. It was also found that the AEA addition enhanced the flowability as it improved the workability of the fresh concrete. This is similar to the findings found in previous research (Kim et al., 2012 [22] and Tarhan et al., 2021 [31]).

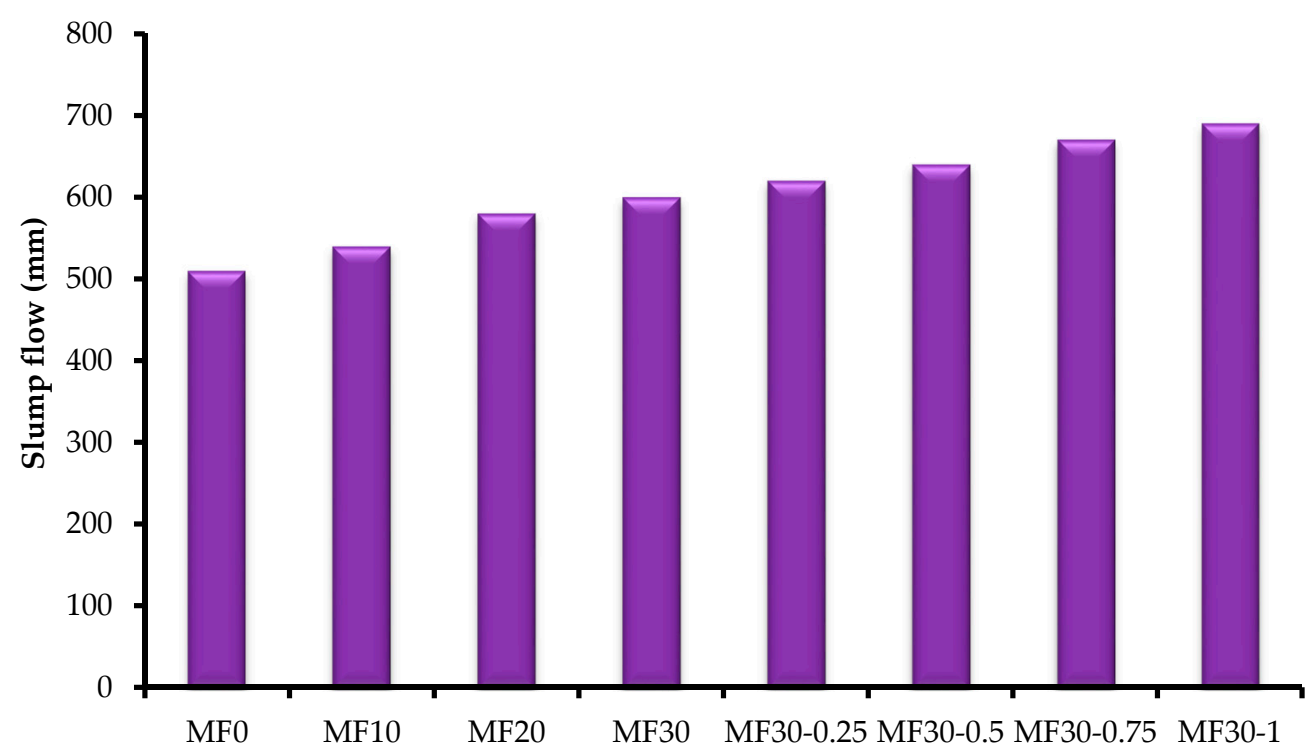

Figure 3. Slump flow.

\subsection{Hardened Properties}

\subsubsection{Dry Density}

Concrete dry density is an important characteristic that has to be studied in SLWAC. According to DIN 1045-1 [41], SLWAC is concrete that has a dry density of less than $2000 \mathrm{~kg} / \mathrm{m}^{3}$ at 28 days. Figure 4 shows the concrete dry density at 28 days. In mixtures containing CBP as filler material, it was observed that increasing the CBP content increased the dry density from $1850 \mathrm{~kg} / \mathrm{m}^{3}$ in MF0 to $1870 \mathrm{~kg} / \mathrm{m}^{3}$ in MF30. This is because CBP 
use filled the voids, and therefore, it caused an increase in the dry density. This is in good agreement with Mobili et al. [19], who found an increase in the concrete density when CBP was used as filler material. In mixtures containing AEA, its addition was observed to cause a significant decrease in the dry density. It decreases with increasing the AEA dosage. This is because it creates air voids, which increase with increasing the amount of AEA in the concrete, causing a lower dry density. These findings are in agreement with previous studies (Deng et al., 2021 [27] and Abd Elrahman et al., 2020 [23]). The lowest dry density was $1746 \mathrm{~kg} / \mathrm{m}^{3}$ in MF30-1.

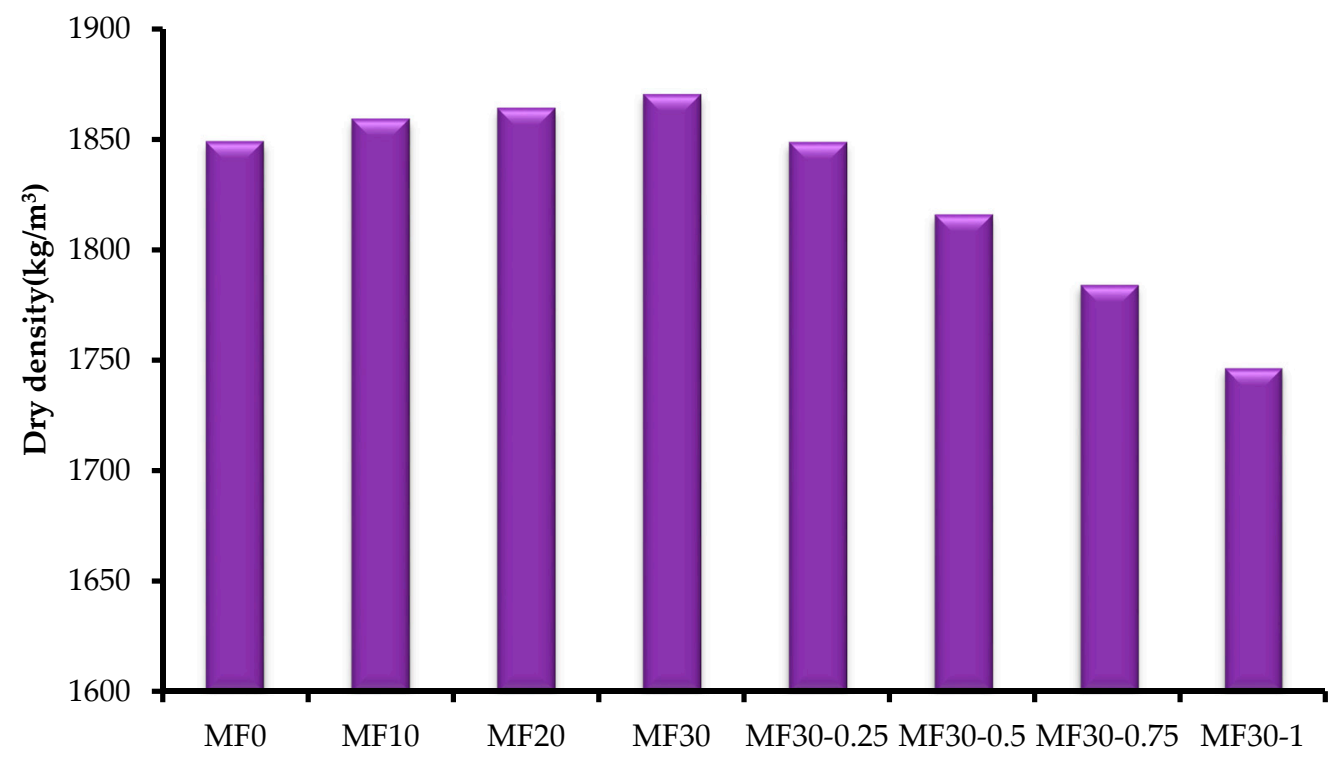

Figure 4. Concrete dry density.

\subsubsection{Compressive Strength}

The mechanical properties of the hardened concrete were evaluated by measuring the compressive strength of the concrete. The values of the compressive strength of the hardened concrete at 7, 28, and 91 days are plotted in Figure 5. The figure indicates that CBP use as filler material enhances the compressive strength at all ages. These results concur with the findings of a previously reported study (Mobili et al., 2018 [19]). The compressive strength increased as the CBP content increased. When using CBP as filler material, the pores were significantly reduced, and the concrete compressive strength increased. The increase in the concrete compressive strength increased with time. This may be because of the pozzolanic activity of the fine particles of the clay brick, which reacts with calcium hydroxide, producing calcium silicate hydrate that fills the pores and increases the compressive strength at later ages. The compressive strength reached $41 \mathrm{MPa}$ at 91 days in MF30. The AEA addition decreased the compressive strength. This is because it creates air-entrained voids in the cement matrix, which makes the concrete weaker. The volume of these voids is related to the content of the AEA. The compressive strength decreased with increasing the AEA content, and this is consistent with previous studies (Chung et al., 2014 [28] and Tarhan et al., 2021 [31]). This decrease is because the air entrained voids would collapse and produce bigger voids when increasing the AEA dosage. The compressive strength decreased from $41 \mathrm{MPa}$ in MF30 to $34 \mathrm{MPa}$ in MF30-1.

All studied mixtures were considered SLWAC because all mixtures had a compressive strength of more than $20 \mathrm{MPa}$ and a dry density of lower than $2000 \mathrm{Kg} / \mathrm{m}^{3}$, which meet the requirements of DIN 1045-1 [41]. 


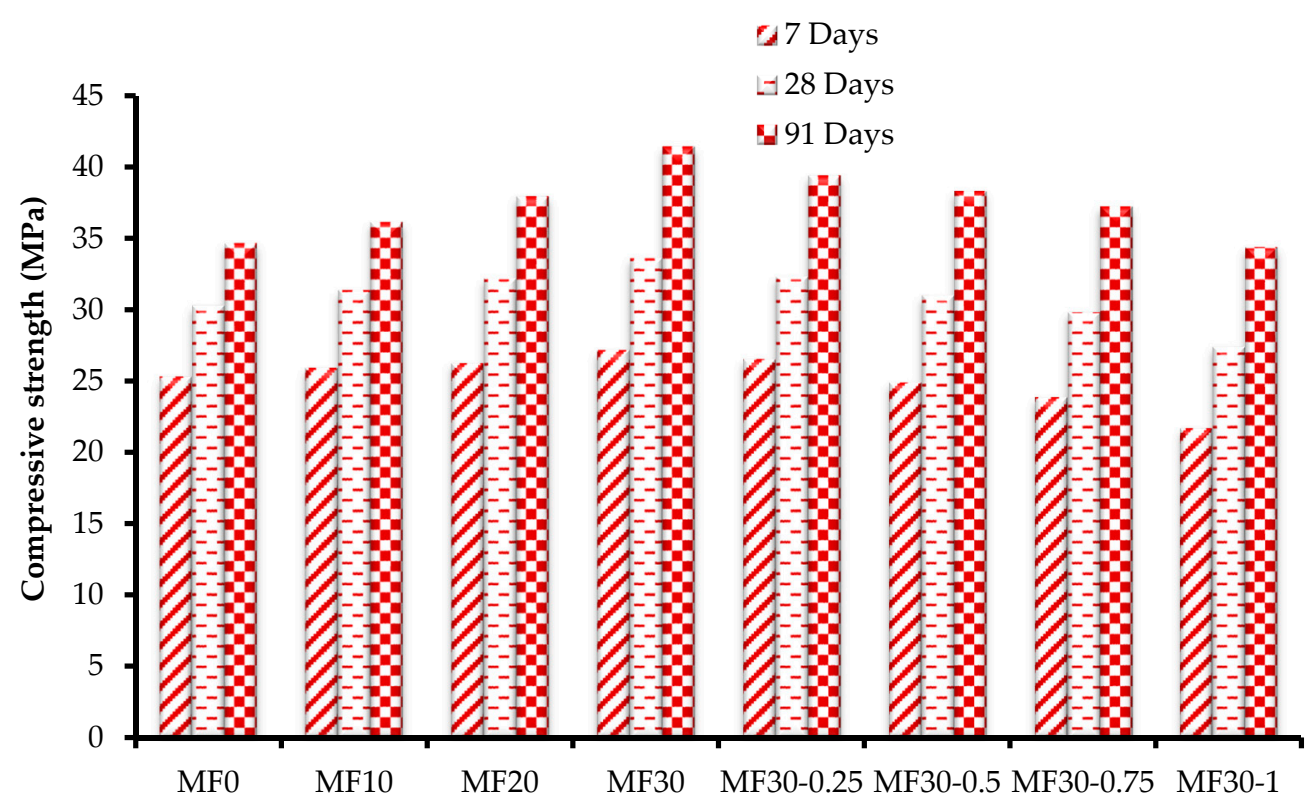

Figure 5. Concrete compressive strength.

\subsubsection{Ultrasonic Pulse Velocity}

The ultrasonic pulse velocity (UPV) values of the concrete after 28 days are indicated in Figure 6. From the figure, it is clear that the UPV value increased when the content of the filler material, CBP, was increased. This is because using CBP as filler material fills the voids, which increases the solid part and decreases the void part. AEA usage reduces UPV values due to the voids that have been generated as a result of adding it. The UPV values increase with using CBP as filler material and decreased with adding AEA.

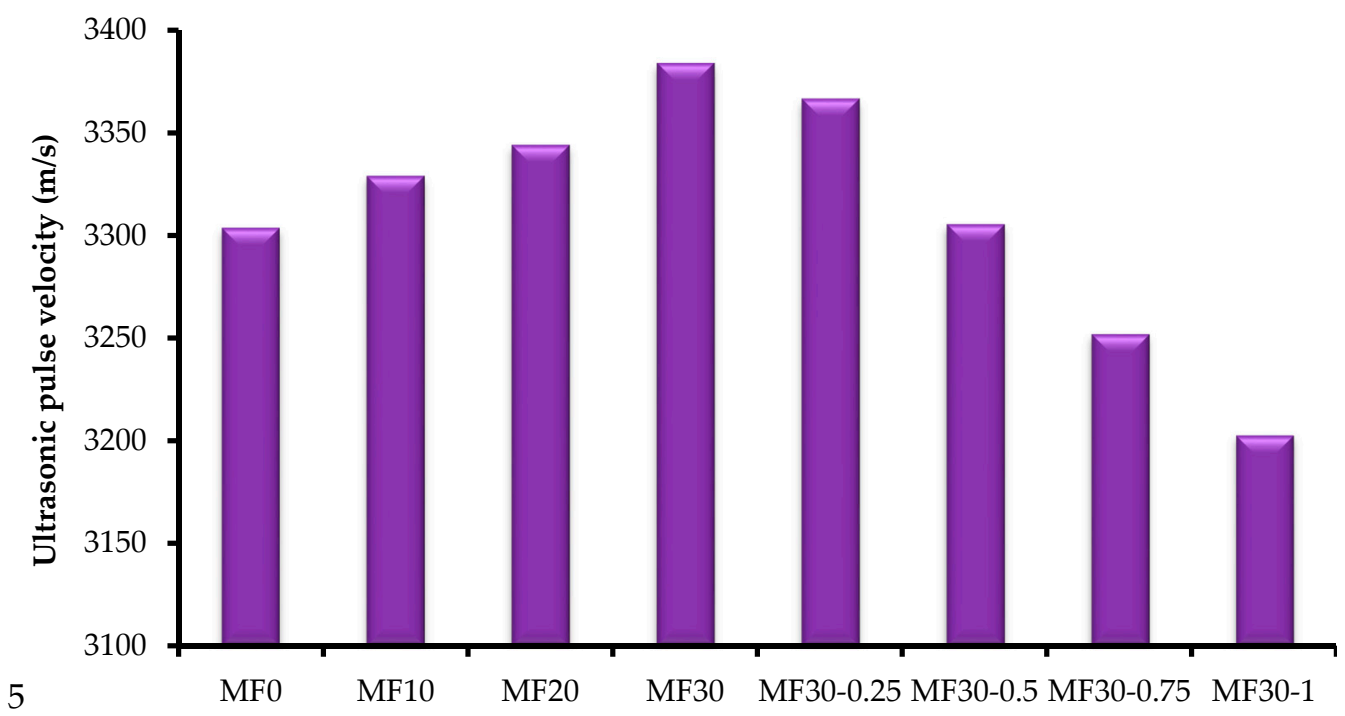

Figure 6. Ultrasonic pulse velocity.

\subsubsection{Thermal Conductivity Coefficient}

The thermal conductivity coefficient of the concrete is related to its density and porosity. The thermal conductivity coefficient values after 28 days are indicated in Figure 7 . Using CBP as filler material in crushed clay brick concrete increased its thermal conductivity. The thermal conductivity coefficient value of MF30 was higher than that of MF0. This is because CBP fills the voids, which increases the thermal conductivity coefficient value as the heat transfers faster in the solid part. It can be seen that using an AEA in concrete reduces its 
thermal conductivity. This is likely due to the air-entrained voids that have been created in the concrete because the AEA was added.

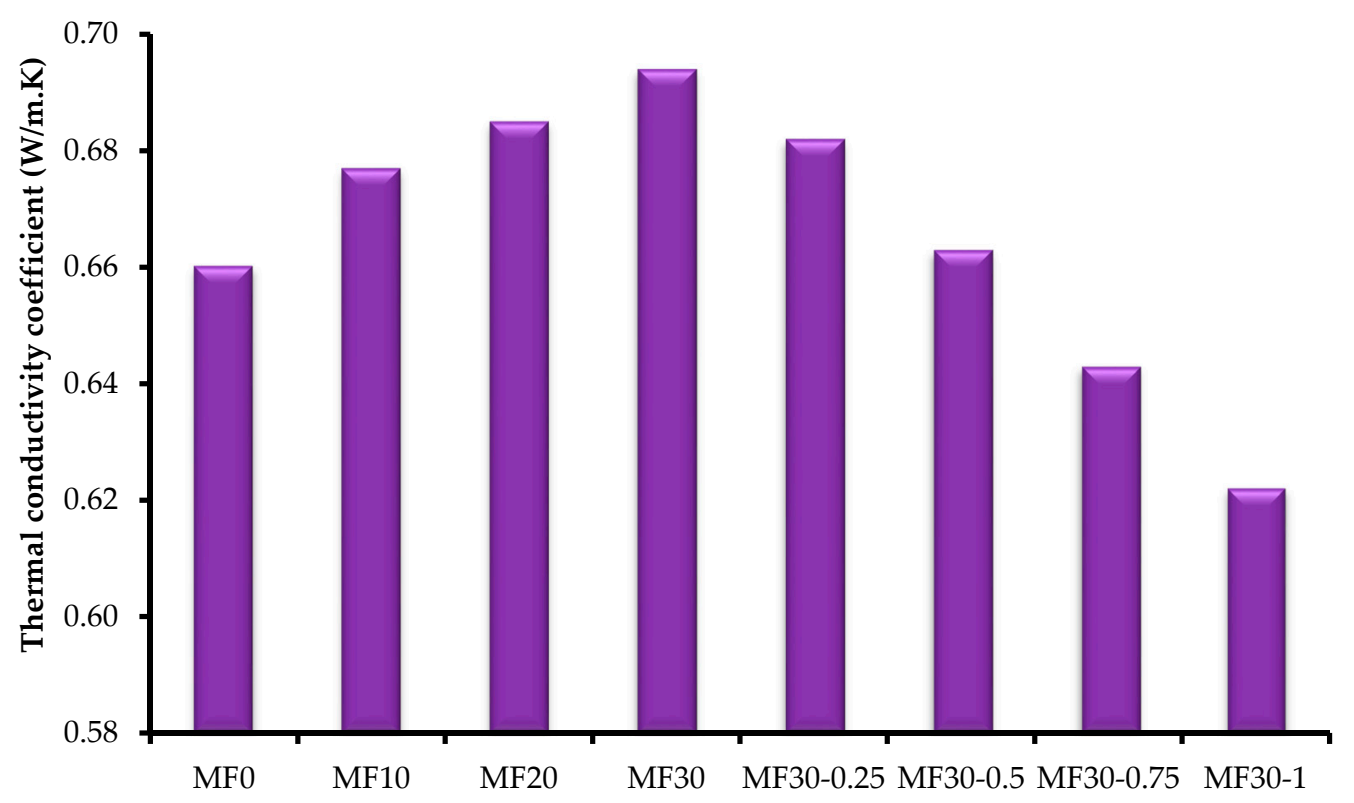

Figure 7. Thermal conductivity coefficient.

\subsubsection{Sorptivity}

Sorptivity was used to assess the durability of the hardened concrete. The sorptivity coefficient results of the concrete after 28 days are indicated in Figure 8. It can be noticed that using CBP as filler material reduced the sorptivity coefficient of the concrete. This is due to the reduction in the pores due to the use of CBP. An increase in the sorptivity coefficient when adding AEA in producing concrete was also found. This indicates that the use of CBP as filler material enhanced the durability of the concrete. In contrast, adding AEA decreased it. This is consistent with (Abd Elrahman et al., 2020 [23]), who found that a greater AEA content leads to a higher sorptivity coefficient.

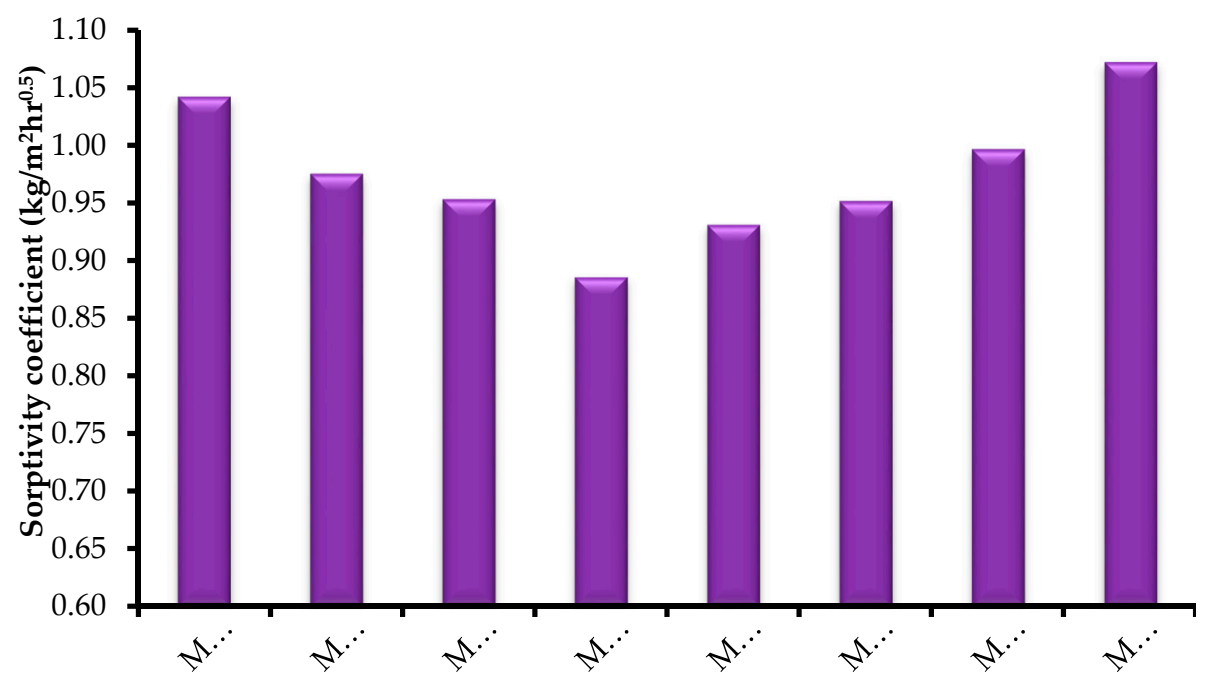

Figure 8. Sorptivity coefficient.

\subsubsection{Porosity}

The concrete porosity was measured using helium pycnometry. Figure 9 shows the concrete porosity at 91 days. The porosity of MF0 at 91 days was $21.54 \%$. It decreased when increasing the CBP content. It reached $19.46 \%$ in MF30. This could be due to the 
denser microstructure that was created by using CBP as a filler material. The utilization of CBP fills the voids and decreases the porosity. For mixes prepared with AEA, the porosity increased with increasing the AEA content. This may be because the AEA produces air bubbles in the hardened concrete. The porosity reached 25.08\% in MF30-1 when using an AEA with a $1 \%$ weight ratio in cementitious materials.

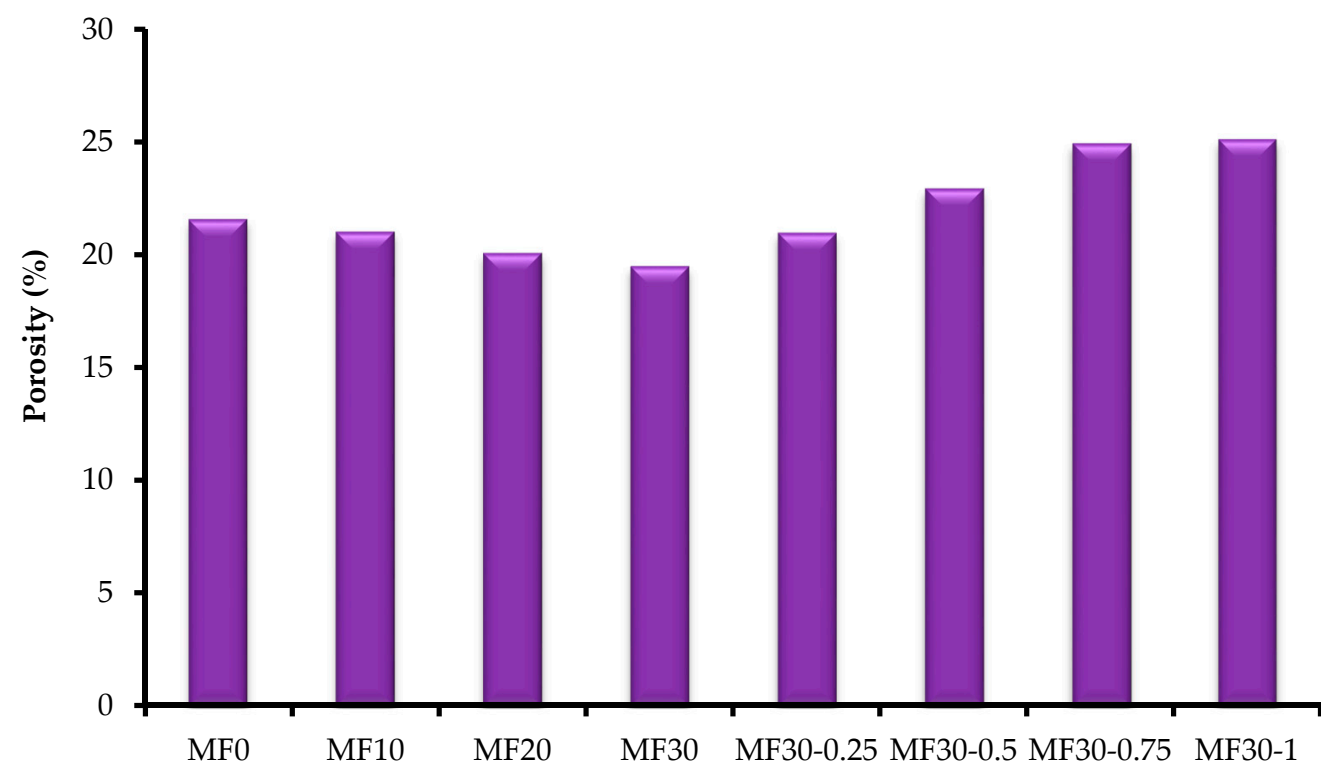

Figure 9. Concrete porosity.

\subsection{Microstructural Investigations}

\subsubsection{Scanning Electron Microscopy (SEM)}

Useful information about the concrete microstructure can be observed from SEM. The effect of using CBP as a filler material has been studied. The SEM micrographs of concrete produced by using $0 \% \mathrm{CBP}$ as filler material (MF0) and concrete produced by using 30\% CBP as filler material (MF30) after 91 days are shown in Figure 10a,b. Pores with a diameter of about $30 \mu \mathrm{m}$ were observed in the MF0 sample, while no pores were observed in the MF30 sample. The micrograph of MF30 shows a denser concrete structure than that of MF0. This is because using CBP reduces the pores.

To study the effect of the AEA, selected samples of MF30, MF30-0.5, and MF30-1 were analyzed using SEM. The SEM micrographs of the mixes MF30, MF30-0.5, and MF30-1 at 91 days are shown in Figure $10 b-d$, respectively. Figure 10b shows that MF30 has a dense concrete structure. A large number of air-entrained voids with a diameter ranging from 3 to $6 \mu \mathrm{m}$ can be observed in Figure 10c. These air voids are small, well-separated, and not connected. Larger pores with a diameter between 150 and $200 \mu \mathrm{m}$ can be seen in Figure $10 \mathrm{~d}$. These larger pores were created from small collapsing air-entrained voids were created by the addition of the AEA.

\subsubsection{X-ray Diffraction (XRD)}

Table 4 indicates the chemical compositions of the XRD diffraction peaks. The XRD patterns of concrete mixtures (MF0 and MF30) at 91 days are shown in Figure 11. Quartz $(\mathrm{Q})$, portlandite $(\mathrm{P})$, calcium silicate $(\mathrm{CS})$, calcium silicate hydrate $(\mathrm{CSH})$, and albite $(\mathrm{A})$ were the main diffraction peaks in MF0 and MF30. Ettringite (E) diffraction peaks were found in MF0 and MF30. This may be because of the use of gypsum as an activator in cement. This may also be due to the reaction of the active alumina in the clay brick. Albite (A) diffraction peaks were seen in MF0 and MF30. This is because of the reaction between the silica fume and the clay brick. The quartz diffraction peaks of MF30 were observed to be higher than those in MF0. This could indicate that the increase in quartz was due to the use of CBP. Calcium silicate diffraction peaks appeared in MF0 and disappeared in 
MF30. Diffraction peaks of CSH are found in MF0 and MF30. Portlandite diffraction peaks in MF0 were higher than those in MF30. This is due to the active silica in the clay brick, which reacts with the portlandite $(\mathrm{CH})$ and produces more $\mathrm{CSH}$.

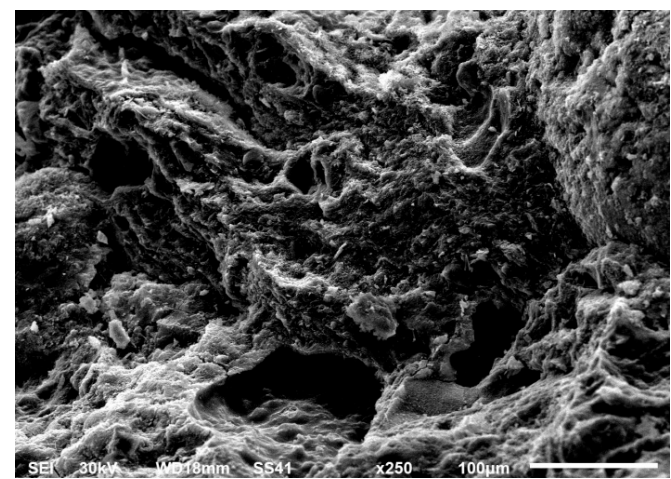

(a) MF0

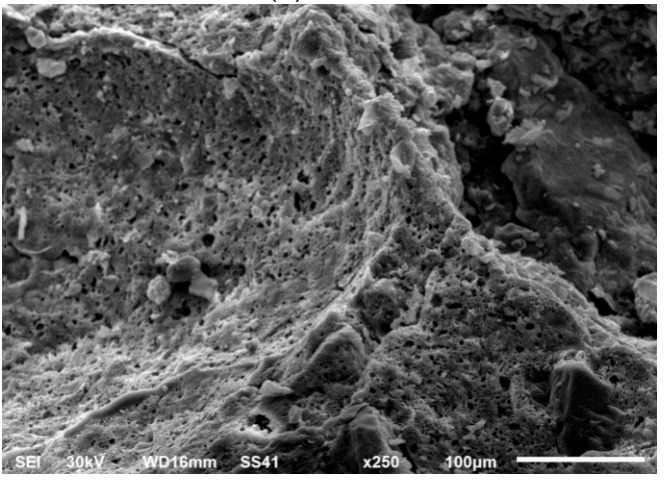

(c) MF30-0.5

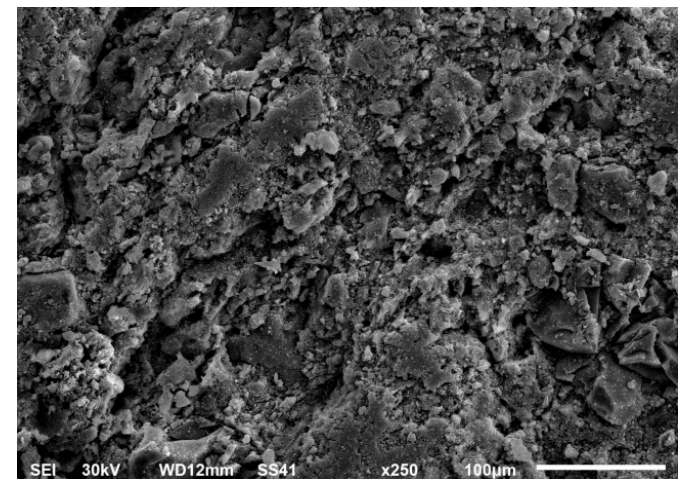

(b) MF30

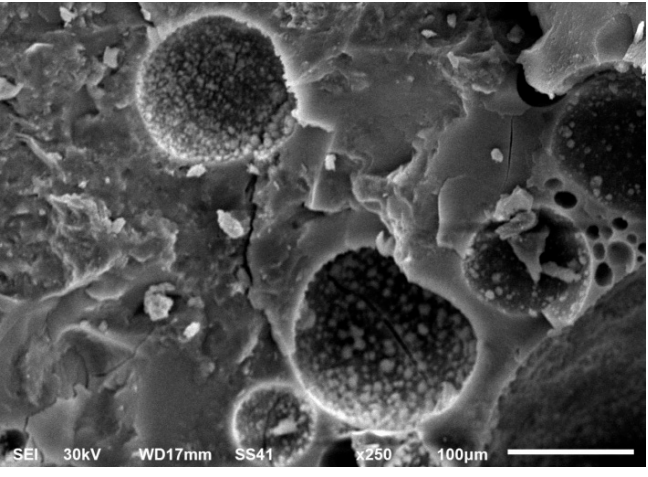

(d) MF30-1

Figure 10. SEM images of concrete. (a) MF0, (b) MF30, (c) MF30-0.5, (d) MF30-1.

Table 4. XRD diffraction peaks.

\begin{tabular}{ccc}
\hline Compound Name & Chemical Formula & ICCD Code * $^{*}$ \\
\hline Albite (A) & $\mathrm{NaAlSi}_{3} \mathrm{O}_{8}$ & $1616-083-01$ \\
Quartz (Q) & $\mathrm{SiO}_{2}$ & $0539-083-01$ \\
Ettringite, syn (E) & $\mathrm{Ca}_{6} \mathrm{Al}_{2}\left(\mathrm{SO}_{4}\right)_{3}(\mathrm{OH})_{12} \cdot 26 \mathrm{H}_{2} \mathrm{O}$ & $1451-041-00$ \\
Portlandite, syn (P) & $\mathrm{Ca}(\mathrm{OH})_{2}$ & $1481-044-00$ \\
Calcium silicate (CS) & $\mathrm{Ca}_{3} \mathrm{SiO}_{5}$ & $0739-055-00$ \\
Calcium silicate hydrate (CSH) & $\mathrm{Ca}_{2} \mathrm{SiO}_{4} \cdot 0.35 \mathrm{H}_{2} \mathrm{O}$ & $0306-033-00$
\end{tabular}

${ }^{*}$ ICDD code: International Centre for Diffraction Data code.

Figure 11 illustrates the XRD patterns of concrete mixtures (MF30, MF30-0.5, and MF30-1) at 91 days. Quartz (Q), albite (A), calcium silicate (CS), and calcium silicate hydrate $(\mathrm{CSH})$ were the main diffraction peaks in these mixtures. Diffraction peaks of ettringite (E) were observed in MF30. This is because of the reaction of the clay brick or the utilization of gypsum as an activator in cement. Portlandite $(\mathrm{P})$ diffraction peaks were observed in MF30. Albite (A) diffraction peaks were found in MF30, MF30-0.5, and MF30-1. This may be due to the reaction between the CBP and the silica fume. CSH diffraction peaks were found in MF30 and MF30-1. Diffraction peaks of calcium silicate are found in MF30-0.5. It was observed that quartz diffraction peaks in MF30 were higher than those in MF30-0.5 and MF30-1. MF30 had the lowest diffraction peaks of quartz, which indicates that quartz was highly consumed in MF30. Quartz diffraction peaks in MF30-0.5 were higher than those in MF30-1. This indicates that the consumption of quartz in MF30-0.5 was higher than that in MF30-1. This may be due to the air voids created from using the AEA. The consumption of quartz is related to the AEA content. 


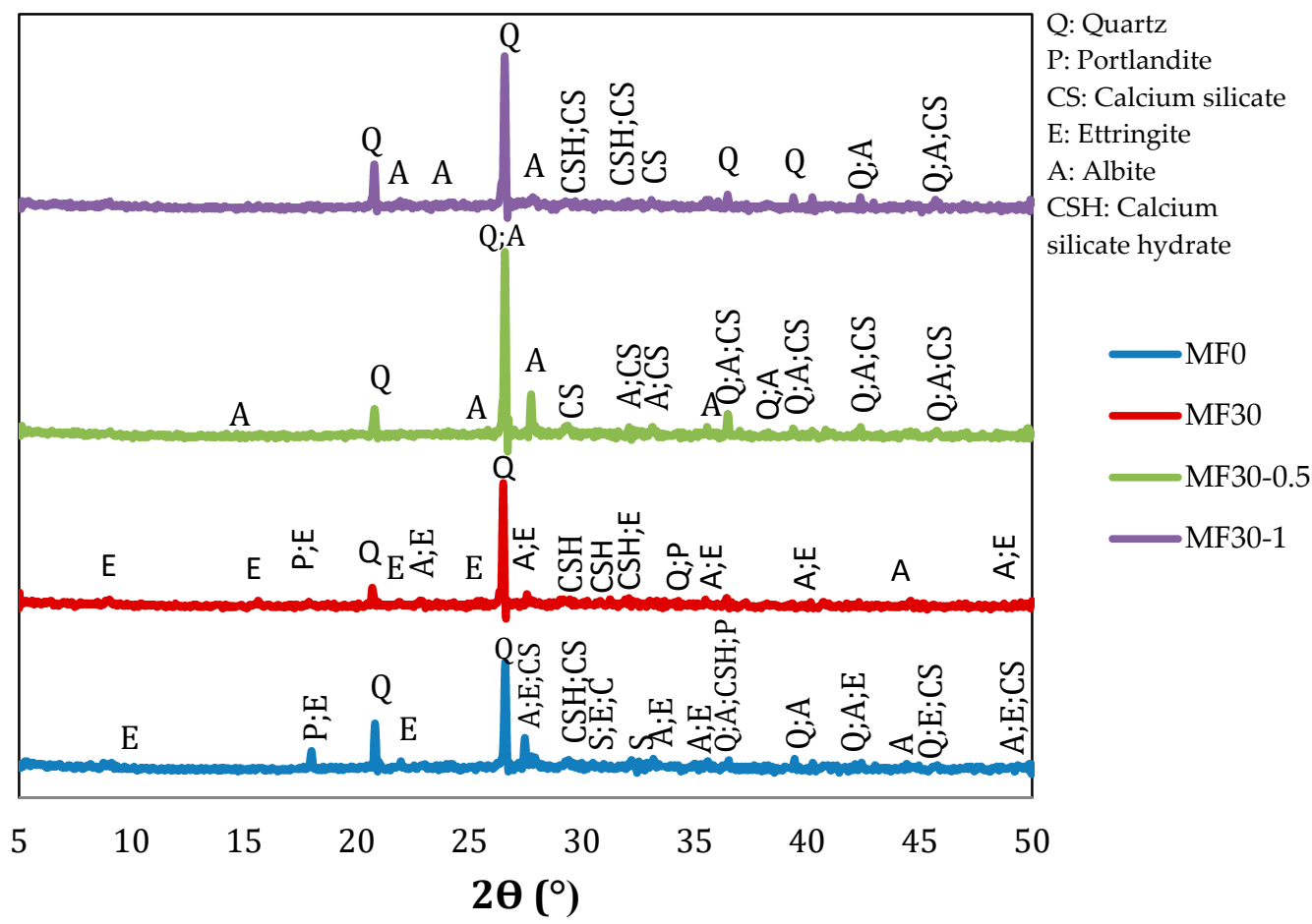

Figure 11. XRD of concrete mixtures (MF0, MF30, MF30-0.5, and MF30-1).

\subsubsection{Thermo-Gravimetric Analysis (TGA)}

Materials can undergo several thermal reactions, which are related to weight changes or heat releases. DTG often shows many weight change reactions, such as the loss of water or $\mathrm{CO}_{2}$. In cementitious systems, weight loss up to $600^{\circ} \mathrm{C}$ is generally related to the loss of water, and weight loss above $600{ }^{\circ} \mathrm{C}$ is mainly due to the release of $\mathrm{CO}_{2}$. Ettringite $\left(3 \mathrm{CaO} \cdot \mathrm{Al}_{2} \mathrm{O}_{3} \cdot 3 \mathrm{CaSO}_{4} \cdot 32 \mathrm{H}_{2} \mathrm{O}\right)$ has a hexagonal prismatic shape. Columns of $\left[\mathrm{Al}(\mathrm{OH})_{6}\right]^{3-}$ octahedra are linked together by calcium and hydroxide ions $\left(\left[\mathrm{Ca}_{6} \mathrm{AI}_{2}(\mathrm{OH})_{12}\right]^{6+}\left[3 \mathrm{SO}_{4}{ }^{2-} \cdot 26 \mathrm{H}_{2} \mathrm{O}\right]^{6-}\right)$, and sulfate and water molecules are located on the outer surface of the columns. The water between the columns was lost at around $100^{\circ} \mathrm{C}$, and continued water loss due to the hydroxides associated with the silica occurs at temperatures up to $400^{\circ} \mathrm{C}$. A peak associated with the weight loss due to $\mathrm{CO}_{2}$ is observed between 600 and $750{ }^{\circ} \mathrm{C}$. Calcium silicate hydrate (C-S-H) phases show water loss over a wide range of temperatures $\left(50\right.$ to $600{ }^{\circ} \mathrm{C}$ ) caused by the loss of the water present in the interlayer and dehydroxylation. $\mathrm{CSH}\left(\mathrm{C}_{1.5} \mathrm{SH}_{2}\right.$ and $\left.\mathrm{CSH}_{1.5}\right)$ diffraction peaks appear between 50 and $200{ }^{\circ} \mathrm{C}$. Calcium hydroxide $\left(\mathrm{Ca}(\mathrm{OH})_{2}\right)$ generally decomposes to $\mathrm{CaO}$ and $\mathrm{H}_{2} \mathrm{O}$ between 400 and $500{ }^{\circ} \mathrm{C}$. Calcite $\left(\mathrm{CaCO}_{3}\right)$ decomposes to $\mathrm{CaO}$ and $\mathrm{CO}_{2}$ between 600 and $800{ }^{\circ} \mathrm{C}$ [42].

Figure 12 presents DTG and TGA curves for MF0 and MF30 at 91 days. Ettringite (E) diffraction peaks were found at about $65^{\circ} \mathrm{C}$. The ettringite diffraction peak in MF0 was lower than that in MF30. This may be due to the reaction of the active alumina in the CBP. $\mathrm{CSH}$ diffraction peaks appeared at about $110^{\circ} \mathrm{C}$ and $200^{\circ} \mathrm{C}$. These diffraction peaks in MF30 were higher than those in MF0. This is because of the pozzolanic reaction of the CBP. Calcium hydroxide $(\mathrm{CH})$ diffraction peaks were observed at about $500{ }^{\circ} \mathrm{C}$. The $\mathrm{CH}$ diffraction peak in MF30 was higher than that in MF0, which indicates that was produced from the reaction of the CBP. Incorporating CBP as filler material increased the $\mathrm{CH}$ and $\mathrm{CSH}$ diffraction peaks as a result of its pozzolanic reaction. 


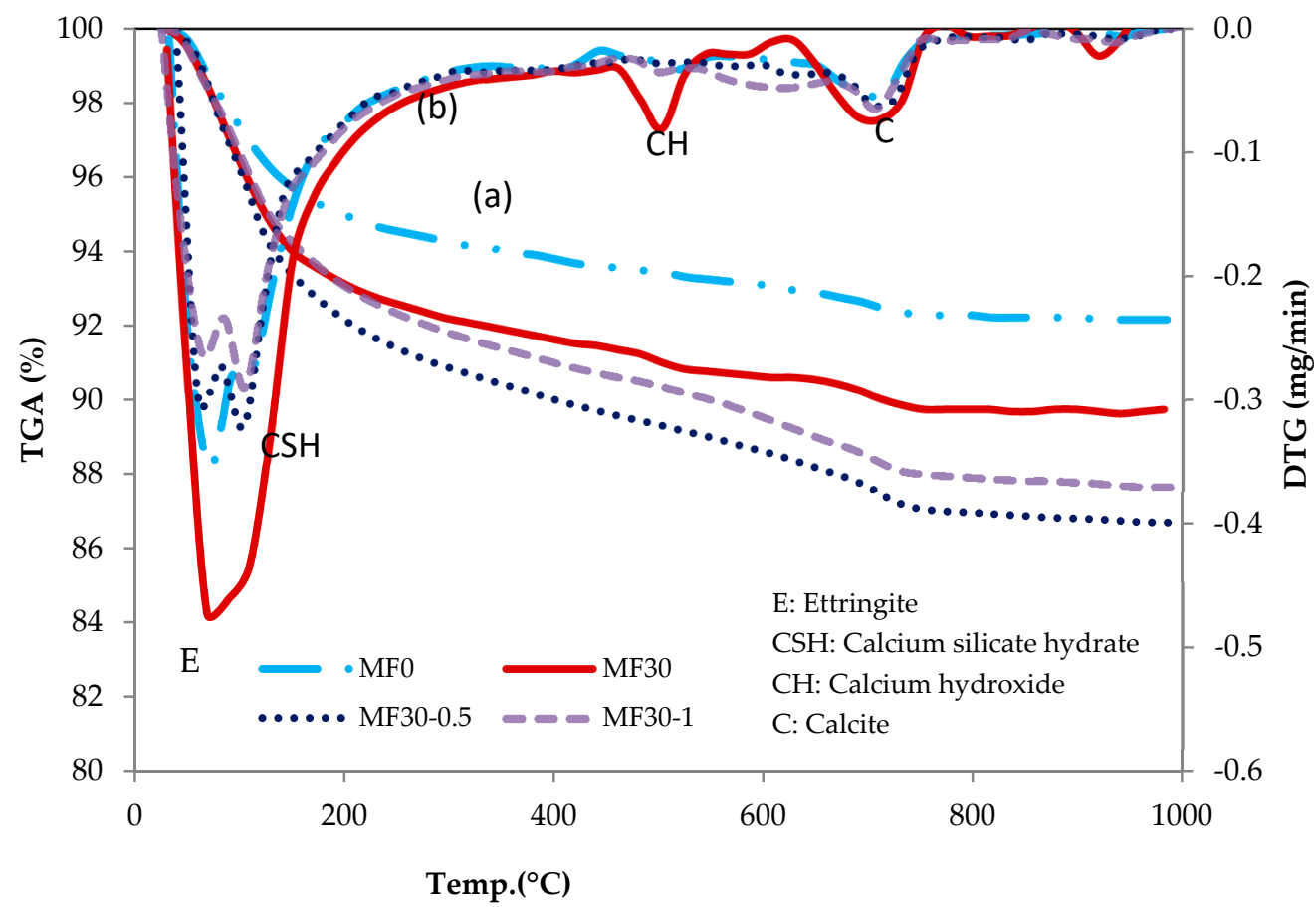

Figure 12. (a) TGA and (b) DTG curves for MF0, MF30, MF30-0.5, and MF30-1.

The DTG and TGA curves for MF30, MF30-0.5, and MF30-1 at 91 days are shown in Figure 12. Ettringite (E) diffraction peaks were observed at $65{ }^{\circ} \mathrm{C}$. Diffraction peaks of $\mathrm{CSH}$ were found at about $110^{\circ} \mathrm{C}$ and $200{ }^{\circ} \mathrm{C}$. $\mathrm{CH}$ diffraction peaks could be seen at about $500{ }^{\circ} \mathrm{C}$. All of these diffraction peaks in MF30 were higher than those in MF30-0.5 and MF30-1. From the figure, it is clear that using the AEA reduced the diffraction peaks of $\mathrm{CH}$ and $\mathrm{CSH}$.

\subsubsection{Mercury Intrusion Porosimetry (MIP)}

The effect of using CBP as filler material on the pore size distribution of the concrete was investigated by using MIP. The average pore diameter was $0.0221 \mu \mathrm{m}$ in MF0 and $0.0193 \mu \mathrm{m}$ in MF30, which indicates that the utilization of CBP as filler material in concrete decreases the diameters of the pores in concrete. The cumulative and incremental pore volume curves for MF0 and MF30 at 91 days are presented in Figure 13. From the curves, it can be observed that the pores in MF30 were smaller than those in MF0. The pores may be classified as gel pores, which have diameters less than $0.01 \mu \mathrm{m}$, capillary pores, which have diameters ranging from $0.01 \mu \mathrm{m}$ to $10 \mu \mathrm{m}$, and air voids, which have diameters up to $10 \mu \mathrm{m}$ [43]. The pore size distribution of concrete mixtures (MF0 and MF30) at 91 days is shown in Figure 14. The use of the CBP as filler material decreased the pore size as the ratios of gel pores in MF30 appeared to be higher than those in MF0. However, the ratios of capillary pores and air voids in MF30 were less than those in MF0. This proves that the use of $\mathrm{CBP}$ as filler material fills the pores and decreases their diameters. 


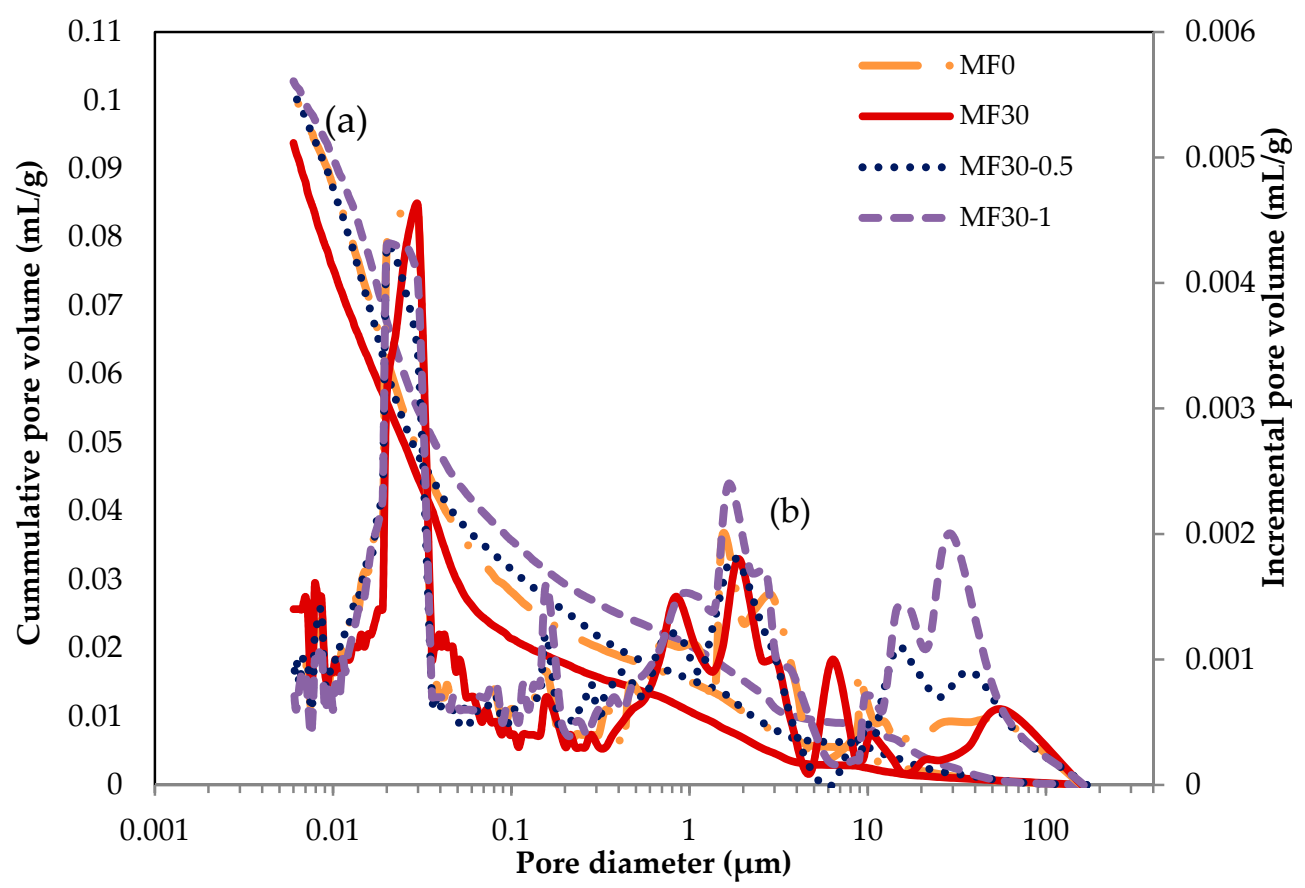

Figure 13. (a) Cumulative and (b) incremental pore volume curves of concrete mixes (MF0, MF30, MF30-0.5, and MF30-1).

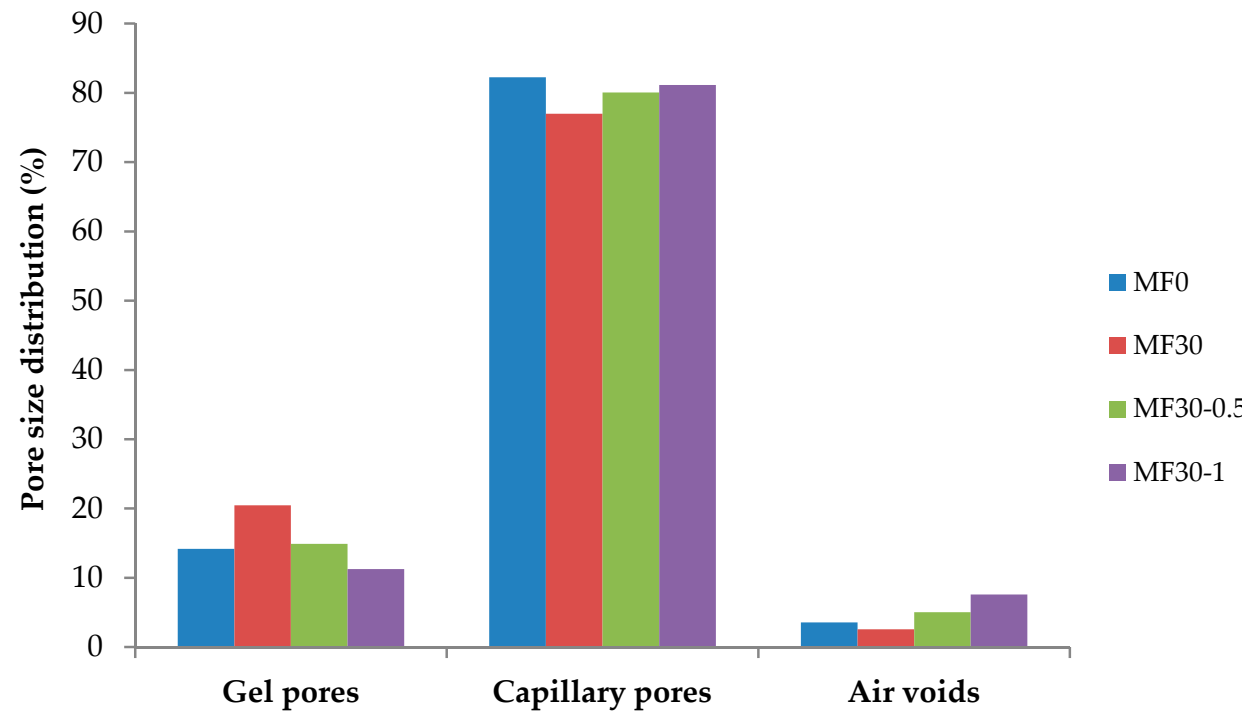

Figure 14. Pore size distribution of MF0, MF30, MF30-0.5, and MF30-1.

The influence of adding an AEA in concrete on the pore size distribution of the concrete was studied using MIP. The average pore diameter was $0.0193 \mu \mathrm{m}$ in MF30, $0.0218 \mu \mathrm{m}$ in MF30-0.5, and $0.0249 \mu \mathrm{m}$ in MF30-1, which indicates that adding an AEA in concrete increases the diameters of the pores in the concrete. The diameters of the pores increase with the increase in the AEA content. The cumulative and incremental pore volume curves of concrete mixtures (MF30, MF30-0.5, and MF30-1) at 91 days are indicated in Figure 13. The pores in MF30 were found to be smaller than those in MF30-0.5 and MF30-1. This indicates that adding AEA increases the size of the pores. The pores in MF30-0.5 ere smaller than those in MF30-1. The pores increased with increasing the AEA content. Figure 14 presents the pore size distribution of MF30, MF30-0.5, and MF30-1 at 91 days. The ratios of gel pores in MF30 were found to be higher than those in MF30-0.5 and MF30-1. It was also found that the ratios of gel pores in MF30-0.5 were less than those in MF30-1. A decrease in 
the gel pores was observed when using the AEA in concrete, and this decrease increased with the increase in AEA content. From the figure, it can be noted that the ratios of capillary pores and air voids in MF30 were found to be less than those in MF30-0.5 and MF30-1. This indicates that the addition of an AEA in concrete increases the capillary pores and air voids. The capillary pores and air voids in MF30-0.5 were smaller than those in MF30-1. This indicates that the utilization of an AEA in concrete increases the capillary pores and air voids. An increase in the capillary pores and air voids was found with the increase in AEA content. This proves that increasing the AEA content increases the diameters of the pores as the small pores collapse and become bigger.

\section{Conclusions}

The effects of using CBP as filler material and adding an AEA in crushed clay brick concrete were investigated. The following conclusions were obtained from the results:

1. The use of CBP as a filler material increases the concrete workability. It also caused an increase in the concrete dry density, compressive strength, UPV values, and thermal conductivity with the increase in the CBP content as it filled the pores and therefore enhanced the mechanical and durability properties of the concrete. There was an observed decrease in the concrete porosity when the CBP was used as filler material. Microstructural investigations (SEM, XRD, TGA, and MIP) proved that using CBP as a filler material decreases the capillary pores and air voids in the concrete; this is due to its filling ability and pozzolanic activity, which caused an increase in the CSH content.

2. Adding an AEA in concrete increases its workability. However, it decreases the concrete dry density, compressive strength, UPV values, and thermal conductivity when the AEA content is increased in the concrete due to the created voids. These voids negatively affect the mechanical and durability properties of concrete but improve its thermal properties. An increase was also found in the concrete porosity while increasing the AEA content. Microstructural investigations (SEM, XRD, TGA, and MIP) proved that adding an AEA in concrete decreases the formation of CSH and increases the capillary pores and air voids, and this is related to the amount of the AEA.

Author Contributions: H.A.-k.; Conceptualization, funding acquisition, writing, and supervision, M.M.A.; Data curation, formal analysis, methodology, writing, resources, M.G.M.; Conceptualization, supervision, review, M.A.E.; Conceptualization, methodology, formal analysis, writing review and editing, supervision. All authors have read and agreed to the published version of the manuscript.

Funding: This research received no external funding.

Acknowledgments: The authors express their sincere gratitude for the financial support provided by the Deanship of The Scientific Research University of Jordan.

Conflicts of Interest: The authors declare no conflict of interest.

\section{References}

1. Debieb, F.; Kenai, S. The use of coarse and fine crushed bricks as aggregate in concrete. Constr. Build. Mater. 2008, 22, 886-893. [CrossRef]

2. Zhao, Y.; Gao, J.; Chen, F.; Liu, C.; Chen, X. Utilization of waste clay bricks as coarse and fine aggregates for the preparation of lightweight aggregate concrete. J. Clean. Prod. 2018, 201, 706-715. [CrossRef]

3. Duan, Z.; Hou, S.; Xiao, J.; Singh, A. Rheological properties of mortar containing recycled powders from construction and demolition wastes. Constr. Build. Mater. 2020, 237, 117622. [CrossRef]

4. Atyia, M.M.; Mahdy, M.G.; Abd Elrahman, M. Production and properties of lightweight concrete incorporating recycled waste crushed clay bricks. Constr. Build. Mater. 2021, 304, 124655. [CrossRef]

5. Wong, C.L.; Mo, K.H.; Yap, S.P.; Alengaram, U.; Ling, T.C. Potential use of brick waste as alternate concrete-making materials: A review. J. Clean. Prod. 2018, 195, 226-239. [CrossRef]

6. Zhu, L.; Zhu, Z. Reuse of clay brick waste in mortar and concrete. Adv. Mater. Sci. Eng. 2020, 2020. [CrossRef]

7. Hansen, T.C. (Ed.) Recycling of Demolished Concrete and Masonry; CRC Press: Boca Raton, FL, USA, 1992. 
8. Janotka, I.; Martauz, P.; Bačuvčík, M. Design of Concrete Made with Recycled Brick Waste and Its Environmental Performance. Minerals 2021, 11, 463. [CrossRef]

9. Cachim, P.B. Mechanical properties of brick aggregate concrete. Constr. Build. Mater. 2009, 23, 1292-1297. [CrossRef]

10. Ibrahim, N.M.; Salehuddin, S.; Amat, R.C.; Rahim, N.L.; Izhar, T.N.T. Performance of lightweight foamed concrete with waste clay brick as coarse aggregate. Apcbee Procedia 2013, 5, 497-501. [CrossRef]

11. Yang, J.; Du, Q.; Bao, Y. Concrete with recycled concrete aggregate and crushed clay bricks. Constr. Build. Mater. 2011, 25, 1935-1945. [CrossRef]

12. Zong, L.; Fei, Z.; Zhang, S. Permeability of recycled aggregate concrete containing fly ash and clay brick waste. J. Clean. Prod. 2014, 70, 175-182. [CrossRef]

13. Zheng, C.; Lou, C.; Du, G.; Li, X.; Liu, Z.; Li, L. Mechanical properties of recycled concrete with demolished waste concrete aggregate and clay brick aggregate. Results Phys. 2018, 9, 1317-1322. [CrossRef]

14. Bektas, F.; Wang, K.; Ceylan, H. Effects of crushed clay brick aggregate on mortar durability. Constr. Build. Mater. 2009, 23, 1909-1914. [CrossRef]

15. Dang, J.; Zhao, J.; Hu, W.; Du, Z.; Gao, D. Properties of mortar with waste clay bricks as fine aggregate. Constr. Build. Mater. 2018, 166, 898-907. [CrossRef]

16. Khatib, J.M. Properties of concrete incorporating fine recycled aggregate. Cem. Concr. Res. 2005, 35, 763-769. [CrossRef]

17. Mobili, A.; Giosuè, C.; Corinaldesi, V.; Tittarelli, F. Bricks and concrete wastes as coarse and fine aggregates in sustainable mortars. Adv. Mater. Sci. Eng. 2018, 2018. [CrossRef]

18. Aliabdo, A.A.; Abd-Elmoaty, A.E.M.; Hassan, H.H. Utilization of crushed clay brick in cellular concrete production. Alex. Eng. J. 2014, 53, 119-130. [CrossRef]

19. Sikora, P.; Rucinska, T.; Stephan, D.; Chung, S.Y.; Abd Elrahman, M. Evaluating the effects of nanosilica on the material properties of lightweight and ultra-lightweight concrete using image-based approaches. Constr. Build. Mater. 2020, 264, 120241. [CrossRef]

20. Kim, H.K.; Jeon, J.H.; Lee, H.K. Workability, and mechanical, acoustic and thermal properties of lightweight aggregate concrete with a high volume of entrained air. Constr. Build. Mater. 2012, 29, 193-200. [CrossRef]

21. Abd Elrahman, M.; Chung, S.Y.; Sikora, P.; Rucinska, T.; Stephan, D. Influence of nanosilica on mechanical properties, sorptivity, and microstructure of lightweight concrete. Materials 2019, 12, 3078. [CrossRef]

22. Wongsa, A.; Sata, V.; Nuaklong, P.; Chindaprasirt, P. Use of crushed clay brick and pumice aggregates in lightweight geopolymer concrete. Constr. Build. Mater. 2018, 188, 1025-1034. [CrossRef]

23. Noaman, A.T.; Jameel, G.S.; Ahmed, S.K. Producing of workable structural lightweight concrete by partial replacement of aggregate with yellow and/or red crushed clay brick (CCB) aggregate. J. King Saud Univ.-Eng. Sci. 2021, 33, $240-247$.

24. Dolch, W.L. Air-entraining admixtures. In Concrete Admixtures Handbook; William Andrew Publishing: Norwich, NY, USA, 1996; pp. 518-557.

25. Kosmatka, S.H.; Wilson, M.L. Design and Control of Concrete Mixtures, 15th ed.; Portland Cement Association: Skokie, IL, USA, 2011.

26. Deng, X.; Gao, X.; Wang, R.; Gao, M.; Yan, X.; Cao, W.; Liu, J. Investigation of microstructural damage in air-entrained recycled concrete under a freeze-thaw environment. Constr. Build. Mater. 2021, 268, 121219. [CrossRef]

27. Chung, S.Y.; Sikora, P.; Rucinska, T.; Stephan, D.; Abd Elrahman, M. Comparison of the pore size distributions of concretes with different air-entraining admixture dosages using 2D and 3D imaging approaches. Mater. Charact. 2020, 162, 110182. [CrossRef]

28. Schackow, A.; Effting, C.; Folgueras, M.V.; Güths, S.; Mendes, G.A. Mechanical and thermal properties of lightweight concretes with vermiculite and EPS using air-entraining agent. Constr. Build. Mater. 2014, 57, 190-197. [CrossRef]

29. Kubissa, W.; Jaskulski, R.; Grzelak, M. Torrent air permeability and sorptivity of concrete made with the use of air entraining agent and citric acid as setting retardant. Constr. Build. Mater. 2021, 268, 121703. [CrossRef]

30. Tarhan, Y.; Şahin, R. Fresh and Rheological Performances of Air-Entrained 3D Printable Mortars. Materials 2021, 14, 2409. [CrossRef] [PubMed]

31. EN ISO 19595:2017; Aggregates for Concrete. ISO: Geneva, Switzerland, 2017.

32. ES 4756-1; Egyptian Standard Specifications (ES) 4576-1. Cement Part 1: Composition, Specifications and Conformity Criteria for Common Cements. Egyptian Organization for Standardization and Quality (EOS). EOS Egypt: Cairo, Egypt, 2013.

33. ASTM C1240-01; Standard Specification for Use of Silica Fume for Use as a Mineral Admixture in Hydraulic-Cement Concrete, Mortar, and Grout. ASTM International: West Conshohocken, PA, USA, 2017.

34. ASTM C494/C494M-08; Standard Specification for Chemical Admixtures for Concrete. ASTM International: West Conshohocken, PA, USA, 2017.

35. ASTM C260 C260M-10a; Standard Specification for Air-Entraining Admixtures for Concrete. ASTM International: West Conshohocken, PA, USA, 2016.

36. EN 12350: 2019: EN 12350; Testing fresh Concrete, Part 8: Slump-Flow Test. Swedish Institute for Standards: Stockholm, Sweden, 2019.

37. EN 12390-7: DIN EN 12390-7; Prüfung von Festbeton-Teil 7: Dichte von Festbeton. Beuth Verlag GmbH : Berlin, Germany, 2009. Available online: https:/ / dx.doi.org/10.31030/1511392(accessed on 1 December 2021).

38. BS EN 12390; Testing Hardened Concrete-Part 3: Compressive Strength of Test Specimens. European Standards Institution: Brussels, Belgium, 2019.

39. ASTM C 597-16: ASTM C 597; Standard Test Method for Pulse Velocity through Concrete. ASTM International: West Conshohocken, PA, USA, 2016. 
40. EN ISO 15148: DIN EN ISO 15148; Bestimmung des Wasseraufnahmekoeffizienten bei Teilweisem Eintauchen. ISO: Geneva, Switzerland, 2002. Available online: https:/ / dx.doi.org/10.31030/3002895(accessed on 1 December 2021).

41. Tragwerke aus Beton, Stahlbeton und Spannbeton-Teil 1, "Bemessung und Konstruktion". DIN 1045-1. Available online: https:/ / www.baunormenlexikon.de/norm/din-1045-1/1ce039fc-a3e6-4f97-a670-38950b599945 (accessed on 1 December 2021).

42. Scrivener, K.; Snellings, R.; Lothenbach, B. (Eds.) A Practical Guide to Microstructural Analysis of Cementitious Materials; Boca CRC Press: Raton, FL, USA, 2016; Volume 540.

43. Aligizaki, K.K. Pore Structure of Cement-Based Materials: Testing, Interpretation and Requirements; CRC Press, Taylor \& Francis Group: London, UK, 2005. 